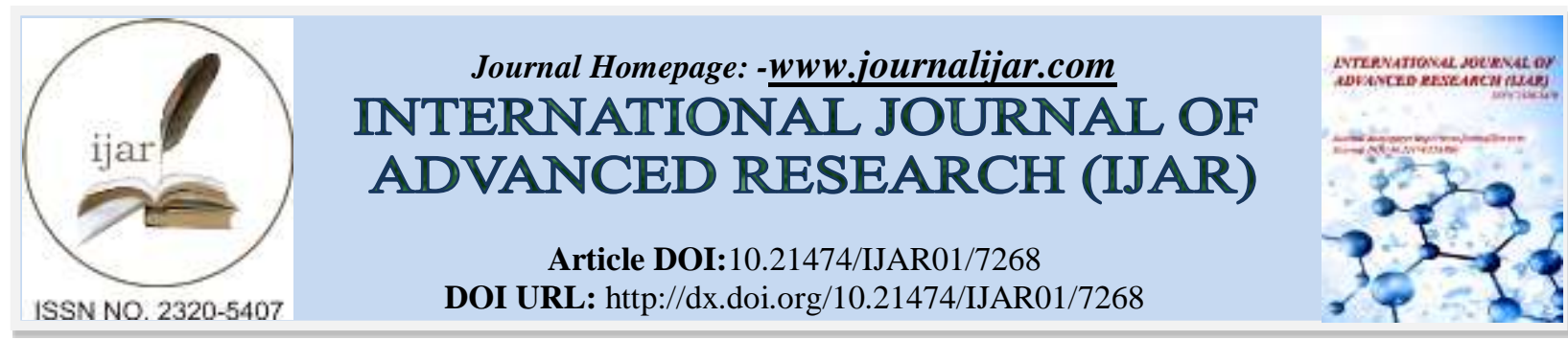

RESEARCH ARTICLE

\title{
E-COMMERCE vs WOMEN ENTREPRENEURS.
}

Dr. Sonia Justin Raj ${ }^{1}$, Mr. Anshul Vyas ${ }^{2}$ and Mr. Bhanu Pratap Singh Rathore ${ }^{2}$.

1. Assistant Professor D.Y. Patil University School of Management, Sector-4, CBD Belapur, Navi Mumbai, India.

2. D.Y. Patil University School of Management, Sector-4, CBD Belapur, Navi Mumbai, India.

\section{Manuscript Info}

Manuscript History

Received: 12 April 2018

Final Accepted: 14 May 2018

Published: June 2018

Keywords:-

Women entrepreneur, E-commerce,

Online Industry, Challenges.

\section{Abstract}

In today's world, women play a major role in every field. Likewise, women are penetrating the e-commerce field and are rising up to face challenges and gain victory one step at a time. This research paper is designed to study the challenges faced by women entrepreneurs in the online e-commerce industry. It is conducted by analyzing the responses received by 25 women entrepreneurs from the e-commerce industry based on various parameters of the challenges faced by them at various intervals.

Copy Right, IJAR, 2018,. All rights reserved.

\section{Introduction:-}

In the $18^{\text {th }}$ Century, entrepreneurship was defined as the process which involves the purchase of goods at a specific price and selling them at a higher price. As the time passes, the term of entrepreneurship widened and the factors of production were imbibed together along with the factors of risk to enhance productivity. A woman entrepreneur is defined as an individual who undertakes risks yet runs a commercial business entity. The International Liberation Organization defined the women enterprise as a small unit where one or more women entrepreneurs have not less than $50 \%$ of financial holdings. E-Commerce or electronic commerce, deals with the buying and selling of goods and services, or the transmitting of funds or data, over an electronic platform, mainly the internet.

\section{Objective of the Study:-}

1. To understand the kinds of challenges faced by women in the online industry.

2. To study the factors that would allow women to overcome their challenges.

3. To understand the aspects wherein the online platforms can be used as a boon to the women in businesses.

\section{Literature Review:-}

Manisha Parnami, Dr. Tripti Bisawa, (2015) in the research paper 'The Rise of Indian Women Entrepreneur in Ecommerce' elaborated on the aspects of how women opt for business in e-commerce for expanding their entities, to cover huge market through online industry and the most important advantage for the women is the freedom of selfspace of working from home.

Meeta Jethwa, Chhaya Mishra (2016), in the paper 'A Study of Women Entrepreneur in the E-Commerce Environment in India', analyzed how women converted from housewives to being an entrepreneur. Women are the most efficient and effective part in entrepreneurship. The paper also tried to study the major role played by women in Mohenjo-Daro and Harappa culture. 
Sonu Garg, Dr. Parul Agarwal (2017), in the paper, 'Problems And Prospects Of Woman Entrepreneurship - A Review Of Literature' studied how a women plays a major role in micro, small and medium enterprises(MSME) and increased entrepreneurship led by women will result in greater employment and development of the society.

Ananya Goswami (2016) in the paper 'E-Commerce Adoption by Women Entrepreneurs in India: An application of The UTAUT Model' analyzed how Information and Communication Technology plays a very important role in the success of SME's. It states that there are challenges in the implementation of ICT for women like improper infrastructure, interrupted supply of electricity, narrow network and high cost stands as challenges for women.

Dina Mellita, Widhya Choli (2012) elaborates on the role of women in business that acts as most important as they help in creating job opportunities and thus leading to the development in economy. In this era wherein there is growing importance of women in businesses, E-Commerce plays a main role in women empowerment.

Supreet Junejawahee, Vaishali Garg, Shashank Gupta (2016) showed how women came out from the restricted boundaries of their home and became independent thus becoming entrepreneurs. The paper also elaborates the various advantages that a woman receives by doing business via various E-commerce platforms.

Vibhawari M. Chavan, Dr. Prachi A murkute (2016) suggests the optimum utilization of scarce resource available in the economy and analyses the various reasons that initiates a woman to become an entrepreneur.

Mira Kartiwi, Teddy Surya Gunawan (2013), elaborates on how SME has played a major role in the development of women entrepreneurship in both rural as well as urban areas of Indonesia. Using E-commerce in SME's for business has given women various advantages like expansion of business, reduction in the cost of warehouse.

Eunice Mukolwe, Dr. Jacqueline Korir (2016), shows the role of women in social media that has helped them to emerge in businesses from individuals and becoming helpful in the success of businesses since some services needs instant response, which is possible with ICT.

Dr. Pradeepika (2017) shows women facing many problems in the market like lack of financial support, high cost of production, limited managerial ability, much pressure of family and society and lack of technology and knowledge. Women entrepreneur faced these challenges in the E- business because they have no knowledge about e- business and they receive neither any support nor guidance from any credible sources.

\section{Research Methodology:-}

The research data for the paper is collected via primary and secondary sources. An interview model was initiated wherein women from various sources and backgrounds were interviewed to understand the extent of their challenges. The interview was based on a structured model that was spread across the target audience to gauge the level of their difficulties and challenges. In addition, factors of overcoming those challenges were also analyzed, each question helped in fulfilling the objective of this research. The secondary data, which was used for the creation of the paper, has been collected from various sources like newspapers, online and printed journals and other research works. 


\section{Analysis And Findings:-}

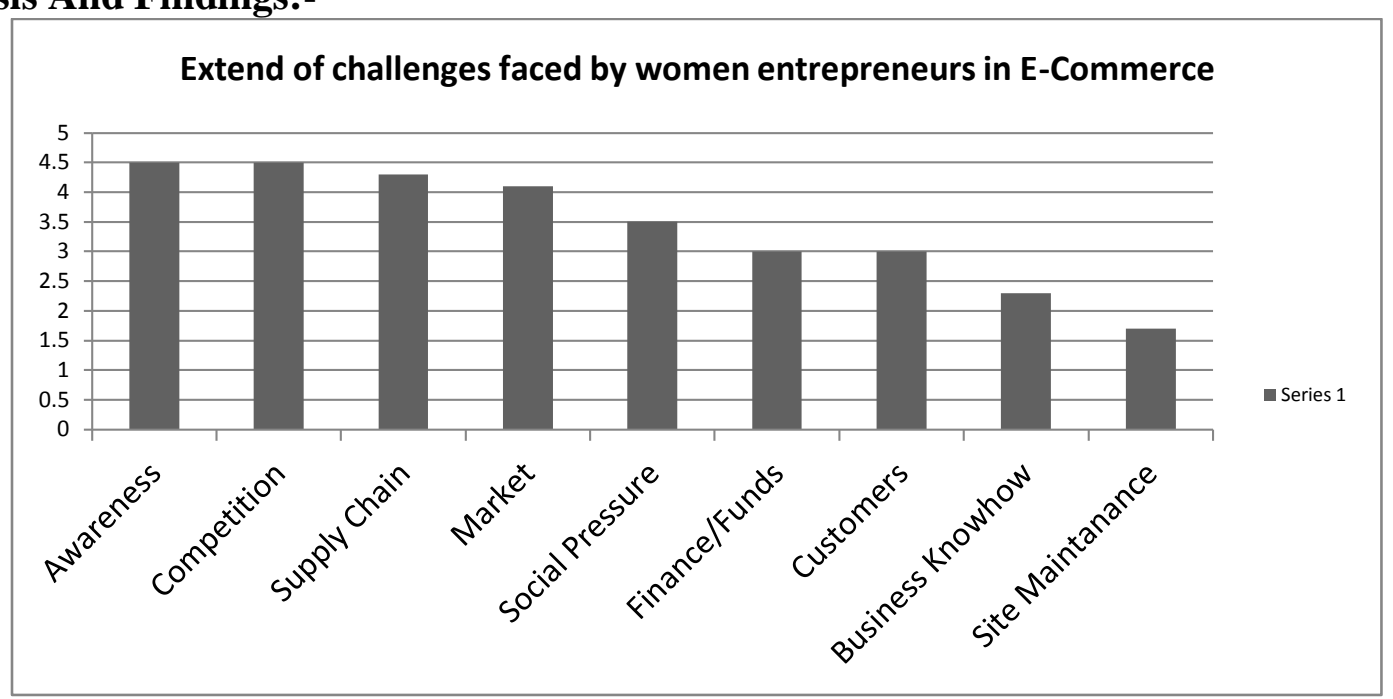

Lack of awareness:-

Education coined with awareness is the most important and essential factor for any business. Literacy ratio is low in developing countries as compared to developed countries. The women are unaware of the various subsidies of the government or even the exemptions they receive in terms of loans and their interest rates. It is a major barrier for women in getting themselves into business smoothly or running the business in an effective and efficient manner.

\section{Competition:-}

Competition amongst the male dominated giant companies comes as a major threat to business run by women. They face challenges of mobility that restricts them to explore and fight back in the competition.

\section{Good supply chain and reliable logistics:-}

For E-commerce business good supply chains and proper logistic is important, the goodwill of the company is majorly dependent on the supply chain. Women majorly specified their dependency on men for the smooth logistics and supply chain functions.

\section{Problem in finding suitable market:-}

Immobility being a major reason, the women entrepreneurs faced problems in finding a target market or niche market.

\section{Finance/Funds:-}

Low creditworthiness stands as a major hurdle amongst women for loans. Funds are the most basic component in any business. Other reasons include fewer properties registered on women. The tedious procedures for procurement of loans make it difficult for women to receive funds for their businesses along with less awareness amongst women in gathering other sources of information for funds.

\section{Problems in retaining customers:-}

Customer Loyalty being an important factor in a business is noticed to be one of the factors of challenge faced by women. Women entrepreneurs must focus on branding and advertisement to gain popularity. Customer retention can also be achieved by offering better quality products at affordable rates than the competitors.

\section{Business Knowhow:-}

It gets difficult for women to run their business and keep up with the updations in terms of trends in business or even technology, due to which they face hurdles in the business and its functioning. 


\section{Conclusion:-}

It can be concluded that the women entrepreneurs must be educated about the women friendly policies of the government, which will help the women to gain much better access to the government schemes and policies, which are designed to make the business much easier and workable for women. The women must move outside the restrains of space and comfort by breaking social boundaries that will allow them to flourish. Sound technical knowledge in the business, which includes the maintenance of the site along with the updations of recent trends in business along with outsourcing capacities in logistics and supply chain.

Women entrepreneurship enables homes to have dual sources of income, which in turn increases the standard of living of the families, and thus increase the standard of the economy in terms of the PPP (purchasing power parity) which in turn develops the economy.

\section{References:-}

1. Manisha Parnami, Tripti Bisawa: The Rise of Indian Women Entrepreneur in E-commerce, IOSR Journal of Business and Management (IOSR-JBM) e-ISSN: 2278-487X, p-ISSN: 2319-7668. Volume 17,Issue 10 .Ver. I (Oct. 2015), PP 36-40

2. http://www.ijacp.org/ojs/index.php/ICBMIS/article/view/44

3. Sonu Garg, Parul Agarwal- Micro, Small and Medium Enterprises in India: A Review of Growth and Challenges in the Present Scenario: International Journal of Applied Business and Economic Research: ISSN : 0972-7302

4. http://www.academia.edu/26710675/A_Study_on_Status_of_Women_Entrepreneur_in_Ecommerce_Environment_in_India

5. E-Commerce Adoption by Women Entrepreneurs in India: An Application of the UTAUT Model, Business and Economic Research, ISSN 2162-4860, 2016, Vol. 6, No. 2

6. Dina Mellita, Widya Cholil, E Commerce and Women Empowerment: Challenge for Women-Owned Small Business in Developing Country

7. Supreet Juneja Wahee, Vaishali Garg, Shashank Gupta-Women Empowerment Through Cyber Entrepreneurship: Implications Through Caselets-ISBN:978-81-931039-1-3

8. Vibhavari M. Chavan, Dr. Prachi A. Murkute - Role Of Women Entrepreneurship In Indian Economy-IJSTMISSN 2394-1537

9. Assessment of e-commerce adoption benefits by Indonesian women entrepreneurs - 5th International Conference on Information and Communication Technology for the Muslim World (ICT4M) - ISBN: 978-14799-0136-4 